\title{
A single case of Rosai-Dorfman disease marked by pathologic fractures, kidney failure, and liver cirrhosis treated with single-agent cladribine
}

\section{Koji Sasaki ${ }^{1}{ }^{\dagger}$, Naveen Pemmaraju ${ }^{1}{ }^{\dagger}$, Jason R. Westin ${ }^{2}$, Wei-Lien Wang ${ }^{3}$, Joseph D. Khoury ${ }^{4}$, Donald A. Podoloff ${ }^{5}$, Bryan Moon ${ }^{6}$, Naval Daver ${ }^{1}$ and Gautam Borthakur ${ }^{1}$}

${ }^{1}$ Department of Leukemia, The University of Texas MD Anderson Cancer Center, Houston, TX, USA

2 Department of Lymphoma and Myeloma, The University of Texas MD Anderson Cancer Center, Houston, TX, USA

${ }^{3}$ Department of Pathology, The University of Texas MD Anderson Cancer Center, Houston, TX, USA

${ }^{4}$ Department of Hematopathology, The University of Texas MD Anderson Cancer Center, Houston, TX, USA

${ }^{5}$ Department of Nuclear Medicine, The University of Texas MD Anderson Cancer Center, Houston, TX, USA

${ }^{6}$ Department of Orthopedic Oncology, The University of Texas MD Anderson Cancer Center, Houston, TX, USA

\section{Edited by:}

Giuseppe Giaccone, Georgetown

University, USA

\section{Reviewed by:}

Giuseppe Giaccone, Georgetown

University, USA

Olatoyosi Odenike, University of

Chicago, USA

\section{*Correspondence:}

Koji Sasaki and Naveen Pemmaraju, Department of Leukemia, The

University of Texas MD Anderson

Cancer Center, 1515 Holcombe Blvd.

Unit 428, Houston, TX 77030, USA

e-mail: ksasaki1@mdanderson.org;

npemmaraju@mdanderson.org

${ }^{\dagger}$ Koji Sasaki and Naveen Pemmaraju

have contributed equally to this work.
Rosai-Dorfman disease (RDD) is a proliferative histiocytic disorder of unknown etiology, which is characterized by sinus histiocytosis with massive lymphadenopathy (1). In most cases, RDD has a benign course and treatment is not necessary. However, severe cases of RDD require treatment, and the treatment strategy is determined on the basis of the severity of the disease or the extranodal involvement of vital organs. We report a single case of RDD with atypical presentation of persistent constitutional symptoms, progressing pathologic fractures, and end-organ dysfunction, including acute kidney failure and liver cirrhosis with esophageal varices.

\section{Keywords: Rosai-Dorfman disease, CD163, S-100, cladribine, histiocytes}

A 55-year-old African American woman presented with a 10-month history of night sweats, fever, weight loss, and hepatosplenomegaly. The patient had experienced an episode of transient renal failure requiring 2 weeks of dialysis 3 months before presentation. Her initial physical exam was significant for no palpable lymphadenopathy.

Positron emission tomography/computed tomography at presentation showed ${ }^{18} \mathrm{~F}$ fluorodeoxyglucose-avid right cardiophrenic, periportal, left gastric, and peripancreatic lymphadenopathy with a maximum node diameter of $3.5 \mathrm{~cm}$ and a maximum standard uptake value of 5.0; hepatosplenomegaly with craniocaudal dimensions of 22 and $14 \mathrm{~cm}$ for the liver and spleen, respectively; and non-displaced rib fractures at right sixth and seventh ribs.

Excisional biopsy of a right axillary lymph node revealed reactive lymph node changes characterized primarily by mantle zone and marginal zone hyperplasia with few small residual germinal centers. Multiple small non-necrotizing granulomas were identified. Sinuses were reactive and contained unremarkable sinus histiocytes without discernible emperipolesis. Immunohistochemistry showed B-cell predominance with minimal paracortical expansion.

Bone marrow biopsy demonstrated that $40-50 \%$ of cellularity with trilineage hematopoiesis. There was no morphologic evidence of infiltration by leukemia, lymphoma, or other malignancy.

Liver biopsy showed established cirrhosis, perisinusoidal fibrosis with prominent proliferation of bile ductal cells, and mild inflammation (predominantly small lymphocytes with a few plasma cells). Esophagogastroduodenoscopy revealed esophageal varices and small varices in the gastric fundus.

Eight months after presentation, the patient developed pathologic fracture of the left ischium. Positron emission tomography/computed tomography showed a lytic lesion involving the left inferior pubic ramus with a soft tissue component measuring $2.5 \mathrm{~cm} \times 1.8 \mathrm{~cm}$ and an associated non-displaced cortical fracture of the left inferior pubic ramus at the site of the lytic lesion (Figure 1).

Surgical biopsy of the left ischium revealed a mixed inflammatory infiltrate composed of large histiocytes, lymphocytes, and plasma cells. The histiocytes demonstrated emperipolesis and were reactive for both CD163 and S-100 proteins; consistent with Rosai-Dorfman disease (RDD) (Figure 2).

The patient was given single-agent cladribine, $5 \mathrm{mg} / \mathrm{m}^{2}$, for days 1 through 5 in 28-day cycles. After five cycles of singleagent cladribine, magnetic resonance imaging confirmed complete resolution of the soft tissue mass in the pubic ramus and a well-healed pathologic fracture. Repeat positron emission 


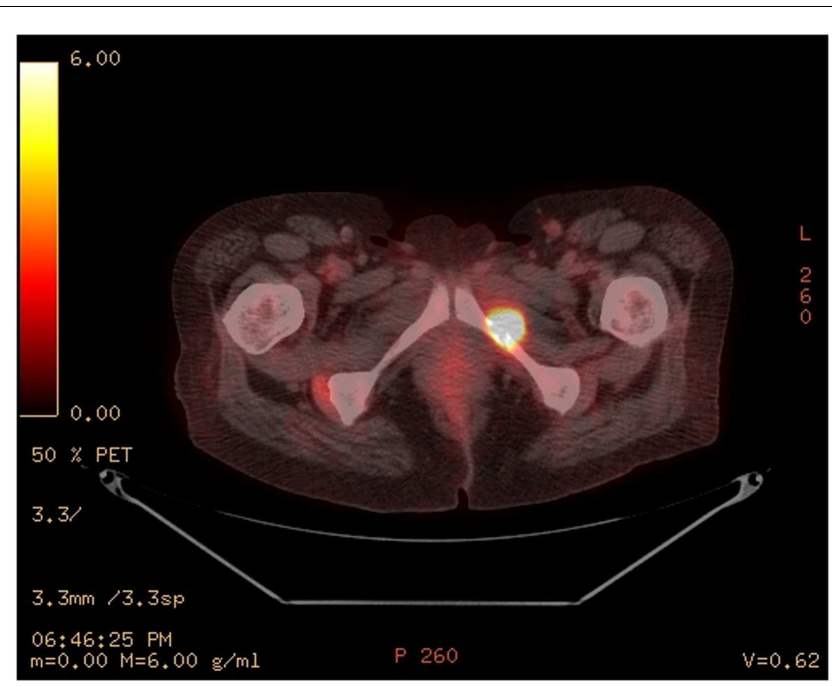

FIGURE 1 | Positron emission tomography/computed tomography of the pelvis showed a hypermetabolic lytic lesion with a pathologic fracture involving the left inferior pubic ramus with maximum SUV 15.1 associated with a soft tissue mass $2.5 \mathrm{~cm} . \times 1.8 \mathrm{~cm}$.

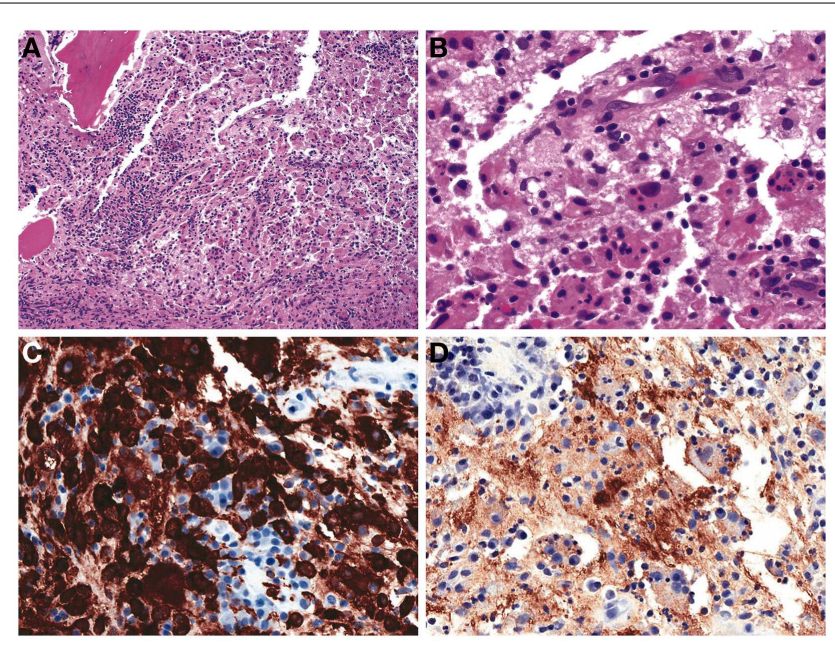

FIGURE 2 | Left ischium biopsy. (A) Collections of histiocytes admixed with lymphocytes are seen involving bone (H\&E, 100x). (B) High power reveals the histiocytes demonstrate emperipolesis, engulfing lymphocytes (H\&E, 400x). Immunohistochemical studies reveal that the histiocytes co-express (C) CD163 and (D) S-100 protein.

tomography/computed tomography showed residual multicompartmental adenopathy and demonstrated no visible ${ }^{18} \mathrm{~F}$ fluorodeoxyglucose uptake.

In our patient, the surgical biopsy of the left ischium demonstrated histiocyte emperipolesis and CD163 and S-100 protein expression. The presence of emperipolesis by histiocytes, which are positive for S-100 and CD163, is diagnostic of RDD (2-4).

Our patient's clinical presentation was atypical because of liver cirrhosis, kidney involvement, and confirmed pathologic fractures. The most frequent clinical presentation of RDD is massive bilateral, painless cervical lymphadenopathy with constitutional symptoms including fever, night sweats, and weight loss (5).

Skeletal lesions of RDD are typically osteolytic and can be confused radiographically with Langerhans cell histiocytosis (5). Extranodal involvement is commonly observed in the upper respiratory tract, skin, and soft tissue and less commonly observed in cases with thyroid, kidney, and skeletal involvement including spine (5-9).

${ }^{18} \mathrm{~F}$ fludeoxyglucose positron emission tomography can detect the metabolically highly active lesions of RDD (10). RDD often takes a self-limited benign course with frequent incidence of spontaneous resolution; nevertheless, approximately $10 \%$ of patients die of RDD due to the extranodal involvement in multiple sites and the progressive proliferation or relapse of systemic lymphadenopathy over several years (11).

In our patient, the persistent constitutional symptoms, progressive pathologic fractures, and end-organ dysfunction - including a previous episode of kidney failure requiring dialysis and liver cirrhosis with esophageal varices - justified further intervention.

Results with chemotherapeutic agents have not been encouraging, although case reports or case series have demonstrated clinical benefits or responses in patients with RDD treated with cladribine (12-15). In our patient, treatment with five cycles of cladribine resulted in radiographic improvement and stable lymphadenopathy without ${ }^{18} \mathrm{~F}$ fluorodeoxyglucose uptake.

In conclusion, the use of chemotherapy should be restricted to patients whose disease is life-threatening, does not respond to conservative treatments, or relapses multiple times after other treatments since RDD is self-limited in most patients. We report a single case of RDD in which treatment with single-agent cladribine resulted in symptom improvement.

\section{ACKNOWLEDGMENTS}

Koji Sasaki and Naveen Pemmaraju equally contributed to write the paper as co-first authors. All authors (Koji Sasaki, Naveen Pemmaraju, Jason R. Westin, Wang Wei-Lien, Joseph D. Khoury, Bryan Moon, Naval Daver, and Gautam Borthakur) edited and reviewed the paper.

\section{REFERENCES}

1. Rosai J, Dorfman RF. Sinus histiocytosis with massive lymphadenopathy. A newly recognized benign clinicopathological entity. Arch Pathol (1969) 87:63-70.

2. Juskevicius R, Finley JL. Rosai-Dorfman disease of the parotid gland: cytologic and histopathologic findings with immunohistochemical correlation. Arch Pathol Lab Med (2001) 125:1348-50.

3. Deodhare SS, Ang LC, Bilbao JM. Isolated intracranial involvement in RosaiDorfman disease: a report of two cases and review of the literature. Arch Pathol Lab Med (1998) 122:161-5.

4. Eisen RN, Buckley PJ, Rosai J. Immunophenotypic characterization of sinus histiocytosis with massive lymphadenopathy (Rosai-Dorfman disease). Semin Diagn Pathol (1990) 7:74-82.

5. Foucar E, Rosai J, Dorfman R. Sinus histiocytosis with massive lymphadenopathy (Rosai-Dorfman disease): review of the entity. Semin Diagn Pathol (1990) 7:19-73.

6. Abdollahi A, Ardalan FA, Ayati M. Extranodal Rosai-Dorfman disease of the kidney. Ann Saudi Med (2009) 29:55-7. doi:10.4103/0256-4947.51823

7. Mrad K, Charfi L, Dhouib R, Ghorbel I, Sassi S, Abbes I, et al. Extra-nodal RosaiDorfman disease: a case report with thyroid involvement. Ann Pathol (2004) 24:446-9. doi:10.1016/S0242-6498(04)94002-3 
8. Miyake M, Tateishi U, Maeda T, Arai Y, Sugimura K, Hasegawa T. Extranodal Rosai-Dorfman disease: a solitary lesion with soft tissue reaction. Radiat Med (2005) 23:439-42.

9. Demicco EG, Rosenberg AE, Bjornsson J, Rybak LD, Unni KK, Nielsen GP. Primary Rosai-Dorfman disease of bone: a clinicopathologic study of 15 cases. Am J Surg Pathol (2010) 34:1324-33. doi:10.1097/PAS.0b013e3181ea50b2

10. Menzel C, Hamscho N, Dobert N, Grunwald F, Kovacs AF, Wolter M, et al. PET imaging of Rosai-Dorfman disease: correlation with histopathology and ex-vivo beta-imaging. Arch Dermatol Res (2003) 295:280-3. doi:10.1007/s00403-0030431-6

11. Lauwers GY, Perez-Atayde A, Dorfman RF, Rosai J. The digestive system manifestations of Rosai-Dorfman disease (sinus histiocytosis with massive lymphadenopathy): review of 11 cases. Hum Pathol (2000) 31:380-5. doi:10.1016/ S0046-8177(00)80254-3

12. Bernard F, Thomas C, Bertrand Y, Munzer M, Landman Parker J, Ouache M, et al. Multi-centre pilot study of 2-chlorodeoxyadenosine and cytosine arabinoside combined chemotherapy in refractory Langerhans cell histiocytosis with haematological dysfunction. Eur J Cancer (1990) 41(2005):2682-9. doi:10.1016/j.ejca.2005.02.007

13. Tasso M, Esquembre C, Blanco E, Moscardo C, Niveiro M, Paya A. Sinus histiocytosis with massive lymphadenopathy (Rosai-Dorfman disease) treated with 2-chlorodeoxyadenosine. Pediatr Blood Cancer (2006) 47:612-5. doi:10.1002/ pbc. 20668

14. Aouba A, Terrier B, Vasiliu V, Candon S, Brousse N, Varet B, et al. Dramatic clinical efficacy of cladribine in Rosai-Dorfman disease and evolution of the cytokine profile: towards a new therapeutic approach. Haematologica (2006) 91:ECR52.

15. Konca C, Ozkurt ZN, Deger M, Aki Z, Yagci M. Extranodal multifocal RosaiDorfman disease: response to 2-chlorodeoxyadenosine treatment. Int J Hematol (2009) 89:58-62. doi:10.1007/s12185-008-0192-2

Conflict of Interest Statement: The authors declare that the research was conducted in the absence of any commercial or financial relationships that could be construed as a potential conflict of interest.

Received: 21 May 2014; accepted: 13 October 2014; published online: 29 October 2014. Citation: Sasaki K, Pemmaraju N, Westin JR, Wang W-L, Khoury JD, Podoloff DA, Moon B, Daver $N$ and Borthakur G (2014) A single case of Rosai-Dorfman disease marked by pathologic fractures, kidney failure, and liver cirrhosis treated with single-agent cladribine. Front. Oncol. 4:297. doi: 10.3389/fonc.2014.00297

This article was submitted to Hematology Oncology, a section of the journal Frontiers in Oncology.

Copyright (c) 2014 Sasaki, Pemmaraju, Westin, Wang, Khoury, Podoloff, Moon, Daver and Borthakur. This is an open-access article distributed under the terms of the Creative Commons Attribution License (CC BY). The use, distribution or reproduction in other forums is permitted, provided the original author(s) or licensor are credited and that the original publication in this journal is cited, in accordance with accepted academic practice. No use, distribution or reproduction is permitted which does not comply with these terms. 